\title{
Seedcoat Structure Related to Germination in Eastern Redbud (Cercis canadensis L.)
}

\author{
Rodney O. Jones and Robert L. Geneve \\ Department of Horticulture and Landscape Architecture, University of Kentucky, Lexington, KY 40546
}

Additional index words. seed dormancy, legume, hilar slit, anatomy

\begin{abstract}
The seedcoat anatomy in the hilar region was examined in dry, imbibed and germinating seeds of Eastern redbud (Cercis canadensis L.). A discontinuous area was observed between macrosclereid cells in the palisade layer of the seedcoat which formed a hilar slit. A cap was formed during germination as the seedcoat separated along the hilar slit and was hinged by the macrosclereids in the area of the seedcoat opposite to the hilar slit. The discontinuity observed in the palisade layer was the remnant of the area traversed by the vascular trace between the funiculus and the seedcoat of the developing ovule. There were no apparent anatomical differences in the hilar region of the seedcoat between dormant and nondormant imbibed seeds. However, the thickened mesophyll of the seedcoat in this region and the capacity of the endosperm to stretch along with the elongating radicle may contribute to maintaining dormancy in redbud seeds.
\end{abstract}

Eastern redbud (Cercis canadensis L.) is a small woody leguminous tree native to eastern North America. It is a member of the subfamily Caesalpinioideae, tribe Cercideae. Eastern redbud is considered a tertiary relic with several primitive anatomical features including a spatulate embryo developing within an anatropous ovule (Comer, 1976). The seed of redbud has a hard impermeable seedcoat with a single palisade layer of macrosclereids that overlies multiple layers of thickened mesophyll cells (Comer, 1976). However, unlike many other temperate woody legumes that display only physical dormancy, eastern redbud also has a physiological dormancy which requires 2-12 weeks of chilling stratification to permit germination (Afanasiev, 1944; Frett and Dirr, 1979).

Eastern redbud has a combined eco- and endodormancy (Lang, et al., 1987). After scarification to render the hard seed permeable to water, a redbud seed requires several months of chilling stratification to overcome endodormancy. However, the embryo will germinate and develop normally if isolated from the seed coverings of a dormant seed (Geneve, 1991).

The seedcoat and endosperm play a role in preventing germination in redbud seeds. This was shown by surgically splitting the seedcoat at the hilar region of the seed where it covers the radicle (Geneve, 1991). Seventy percent of these seeds germinated compared to only $20 \%$ for seeds split at the opposite end. Using an Instron, (Instron, Boston) it was determined that the force required to penetrate the hilar region of the imbibed seed was $11 \%$ greater for dormant compared to nondormant redbud seeds (Geneve, 1991). However, a change in the physical strength of the seedcoat and endosperm could not account totally for its loss of dormancy. This change in the physical properties of the seedcoat and endosperm was also accompanied by a dramatic increase in the growth potential of the embryo calculated during chilling stratification (Geneve, 1991). Growth potential was measured by growth of the radicle from embryos isolated from dormant or nondormant seeds and germinated on solutions with progressively more negative osmotic potentials (Baskin and Baskin, 1971). Embryos from

Received for publication 4 Aug. 1993. Accepted for publication 17 June 1994. Paper no. 94-10- 12 of the Kentucky Agriculture Experiment Station. The authors wish to thank Pam Compton for her technical assistance in the preparation of this manuscript. The cost of publishing this paper was defrayed in part by the payment of page charges. Under postal regulations, this paper therefore must be hereby marked advertisement solely to indicate this fact. nondormant redbud seed showed an $-28 \%$ increase in growth potential (radicle length) compared to embryos excised from dormant seed (Geneve, 1991). A combination of physical changes in the seed coverings (seedcoat plus endosperm) and a modification of the germinating force of the embryo were considered the prime mechanisms for maintaining dormancy in eastern redbud seed (Geneve, 1991).

The seed anatomy of Judas tree (Cercis siliquastrum L.) has been described previously (Comer, 1976; Profumo and Gastaldo, 1977), but has not been detailed for eastern redbud. The objective of this study was to examine the anatomy of the seed coverings in the hilar region of easternredbud. Specifically, this study describes the anatomical changes in the hilar region associated with imbibition and germination. The origin and function of the hilar slit is described and the possible role of the seed coverings in the hilar region are discussed in relation to seed dormancy.

\section{Materials and Methods}

Redbud seed was collected after the pods had desiccated on trees grown on the University of Kentucky, Lexington campus. Seeds were subsequently stored dry at 5C. To allow imbibition, seeds were scarified by immersion in concentrated sulfuric acid for $30 \mathrm{~min}$. Scarified seeds were stratified for 10 weeks at $5 \mathrm{C}$ by placing -50 seeds in $10 \mathrm{ml}$ autoclaved deionized water in a disposable petri dish containing two pieces of Whatman \#1 filter paper. Following stratification, ten seeds were germinated in a petri dish containing $4 \mathrm{ml}$ autoclaved deionized water at $27 \mathrm{C}$ in the dark.

For anatomical studies, seeds were fixed either dry, following imbibition, following stratification or during germination. In addition, developing ovules ( $\approx 57$ days postanthesis) were also fixed for subsequent sectioning.

About $3 \mathrm{~mm}$ at the hilar end of each seed or ovule was removed with a razor blade and fixed for $3 \mathrm{~h}$ in $2 \%$ glutaraldehyde in a 10 mM sodium phosphate buffer ( $\mathrm{pH}$ 7.2). Seeds were then triple rinsed in the sodium phosphate buffer and dehydrated in a graded ethanol series. Dehydrated tissue was embedded in JB-4 resin (Poly-Sciences, Warrington, Penn.) in a flat embedding mold. Tissue blocks were sectioned at $5 \mathrm{~mm}$ using a dry glass blade on a Zeiss HM350 motorized ultramicrotome. Sections were stained with $1 \%$ toluidine blue $\mathrm{O}$ for $30 \mathrm{sec}$, air-dried and placed under a coverslip in Permount. 


\section{Results}

Following 10 weeks of stratification, eastern redbud seeds consistently germinated in a characteristic pattern. The first sign of germination was the development of a crack along a transverse slit in the hilar area of the seed (Fig. la). As the radicle continued to elongate, a cap hinged away from the hilar slit (Fig. lb), releasing the radicle from the seedcoat.

A freehand longitudinal section through a dry seed (Fig. 2a) shows the gross tissue organization in the hilar region. This includes the spatulate embryo, endosperm, multiple cell layers of the mesophyll and the single macrosclereid palisade layer in the seedcoat. The same plane of sectioning is shown in all subsequent photomicrographs. Details of these tissue layers are shown more clearly in fixed and stained section (Figs. 2b and 3b), which includes the protuberance on the seed created by an increased number of cell layers in the mesophyll of the seedcoat. A vascular trace was observed passing through the mesophyll on one side of the seedcoat and terminating at the hilar slit (Figs. 2 a and b, 3 a and b).

The hilar slit in dry and imbibed seeds represents an interruption in the continuous palisade layer of the seedcoat (Figs. 2 and 3). In the dry seed, the terminal macrosclereid cells in the palisade layer contact each other, but a discontinuity in the hilar slit was evident. In imbibed seeds, the macrosclereid cells swell and pull away from each other at the hilar slit (Fig. 3c). This may represent a major area of water uptake in the seed.

Another feature of the macrosclereids at the hilar slit was the location of the light line (Figs. 2d and 3d). In most macrosclereids, the light line was located in the outer one-quarter of the cell (Fig. 4). However, in the macrosclereid cells adjacent to the hilar slit, the light line dipped to the inner quarter of the cell (Fig $2 \mathrm{c}$ and d). After imbibition, the portion of the macrosclereid cells above the light line took on an irregular shape along the area of the hilar slit (Fig. 3 b-d).

During germination of stratified seeds, the seedcoat ruptured at the hilar slit (Fig. 5). Initially, the seedcoat separated at the area of discontinuity in the palisade layer (Fig. 5b). The cells in the mesophyll beneath the hilar slit were tom apart as a seedcoat cap was formed from the pressure of the elongating radicle. The number of cell layers of the endosperm was reduced over the radicle (Figs. 2, 3, and 5). Early in germination, the cells of the endosperm appear to have been stretched over the emerging radicle while the more rigid cells of the mesophyll had already tom (Fig. $5 \mathrm{a}$ and b). Subsequently, the endosperm was split above the root apex (Fig. 5c) and pushed aside ahead of the elongating radicle

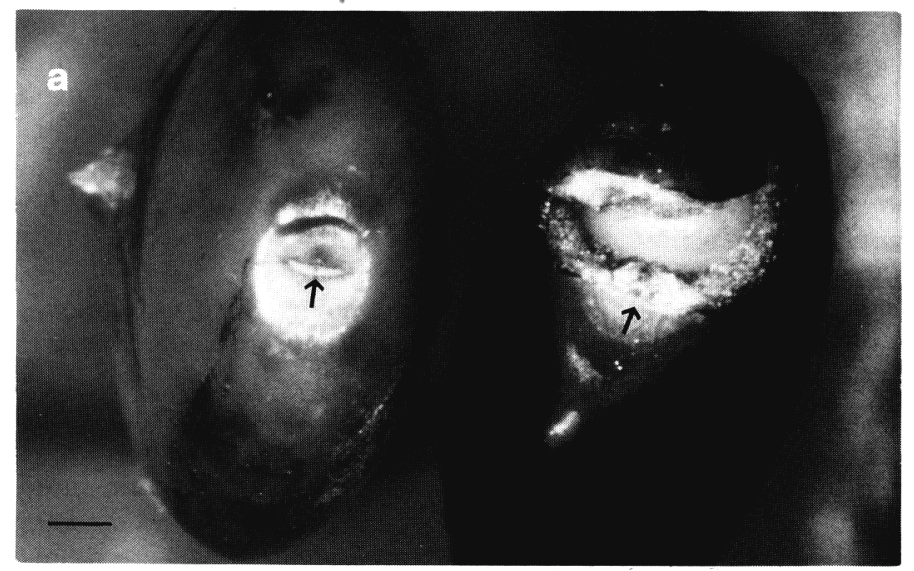

tip (Fig. 5d). During germination, the stretched portion of the endosperm was less densely stained compared to the other areas of the endosperm and the prominent staining in the protein bodies was no longer evident (Fig. $5 \mathrm{~b}$ and c).

During ovule development, the origin of the discontinuity in the palisade layer at the hilar slit became evident. The discontinuity was at the location where the vascular trace traversed between the funiculus and the developing ovule (Fig. 6). Early in seed development, while the embryo was in a rudimentary globular stage, the cell layers of the seedcoat were well developed. The light line in the macrosclereids of the palisade layer were clearly evident. However, the cells in the mesophyll layer of the seedcoat of the hilar area showed only slight cell wall thickening and were more parenchyma-like.

\section{Discussion}

The basic seed anatomy of redbud has been described by Comer (1976) using $C$. siliquastrum. The current work provides the first detailed study in eastern redbud of the portion of the seed covering the radicle and follows changes in this region during germination. The tissue layers in the seed coverings at the hilar region were highly specialized (Fig. 1-3). The endosperm was reduced in thickness to only a few cells, while an increased number of cell layers in the mesophyll of the seedcoat formed a protuberance on the seed. The palisade layer was interrupted in this portion of the seed to form a hilar slit. The anatomical evidence shows that in eastern redbud, the hilar slit acted as a weak point in the seedcoat which split on the commencement of germination (Fig. 5). The pressure of the radicle lifted a cap which was formed as the cells in the mesophyll, beneath the hilar slit, were broken and the cells in the palisade opposite the hilar slit hinged around the protuberance.

There was no anatomical evidence to suggest that there was an obvious change in the seedcoat during chilling stratification that might be associated with the release from dormancy. Gastaldo and Profumo (1975) examined imbibed and germinating seeds of Judas tree ( $C$. siliquastrum) and reached a similar conclusion. They also described a very similar seedcoat anatomy in the hilar region of the seed. However, the anatomical feature referred to here as the hilar slit was described as the trace of micropyle (traccia del micropilo) for Judas tree seed. The micropyle is usually inconspicuous in Caesalpinioid seeds (Gunn, 1981) and although it should be located in the hilar region, it is not obvious in the photomicrographs for eastern redbud or judas tree. We feel that it

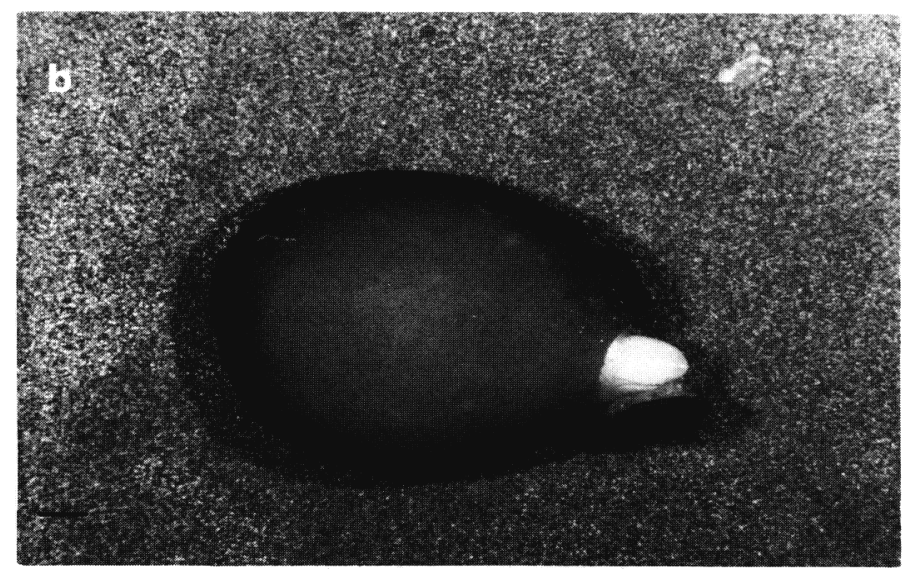

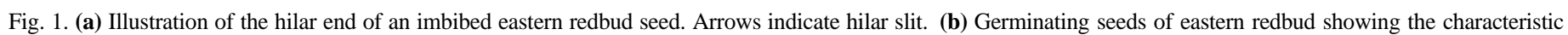
cap formed as the seedcoat separates at the hilar slit allowing the radicle to emerge. Reference bars represents $500 \mu \mathrm{m}$. 
was shown convincingly that the discontinuity in the seedcoat of this region of eastern redbud seed was formed in the hilum as a remnant from the location where the vascular trace connected the funiculus to the ovule (Fig. 6). The characteristic change in location of the light line in macrosclereids at the hilar slit (Figs. 2 and 3) was also evident during seed development (Fig. 6) and provides a marker to localize the hilar slit to the vascular connection between the funiculus and the ovule in developing seeds. The term hilar slit is consistent with the term hilar fissure used to describe a similar region in papilionoid seeds and the chalazal slit described for hard seeds in the Malvaceae.

The hilar slit in Eastern redbud is similar to the chalazal slit described for species in the Malvaceae (Martin and Watt, 1944; Serrato-Valenti et al., 1992; Winter, 1960). In these studies, the chalazal slit was the area of the seedcoat associated with water entry into the seed and the condition of the chalazal slit was critical to maintaining the impermeability of the seed to water. The hilar slit in eastern redbud may have a similar function related to water uptake. For many legume seeds, the lens is the site of water entry into the seed (Kelly and van Staden, 1987). However, the lens is inconspicuous in redbud seed (Gunn, 1981), so the hilar slit may fulfill a similar function to the lens for water uptake. Also, the hilar slit may function in a similar capacity as the hilar fissure described for many papilionoid seeds (Hyde, 1954; Manning and van Staden, 1987), where this discontinuity in the palisade layer functions as a valve to allow water to escape from the seed during desiccation. A major difference between the hilar fissure and the hilar slit de-

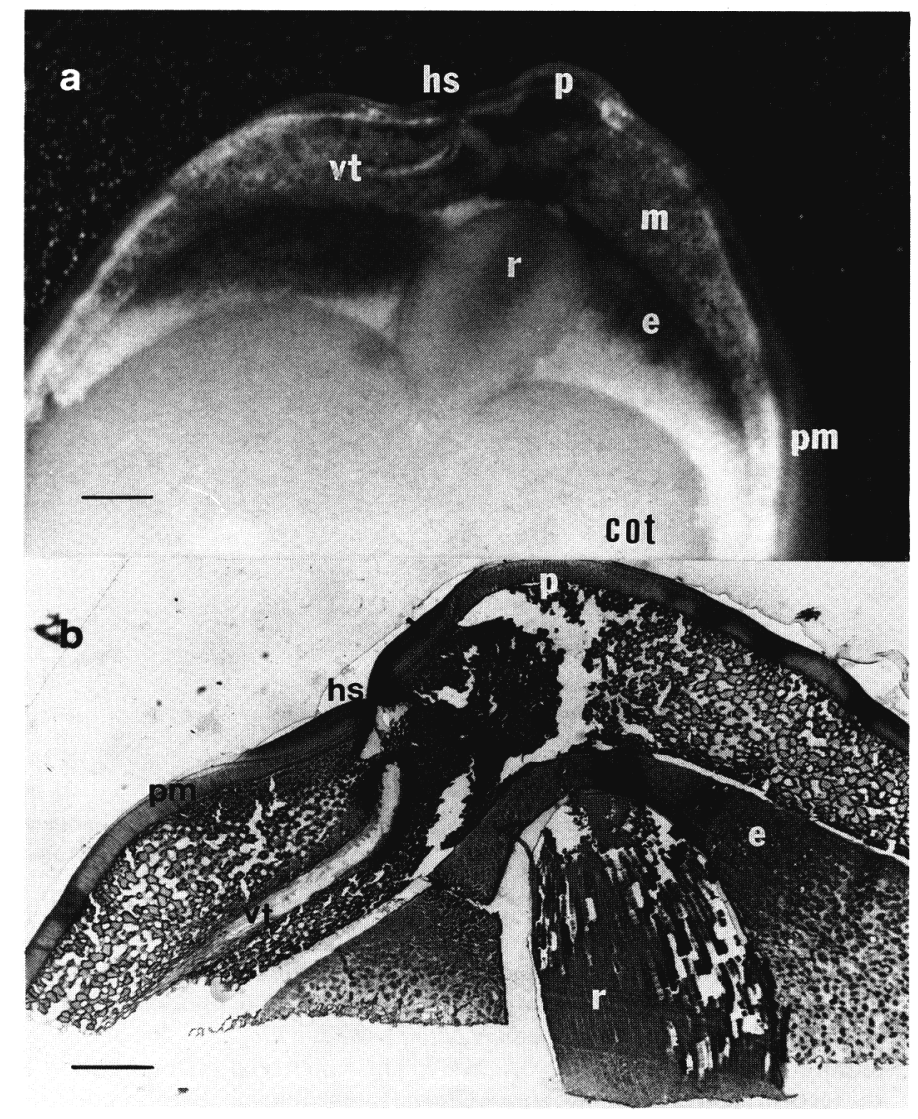

scribed for eastern redbud is the absence of tracheid bars in the mesophyll layer in redbud.

Profumo and Gastaldo (1977), showed that the endosperm presented a physical barrier to germination in de-coated embryos of the Judas tree. A similar de-coating treatment was not possible with eastern redbud seed, but it was noted that the endosperm remained intact and stretched along with the radicle after the seedcoat was cracked (Fig. 5). The endosperm cells covering the radicle during germination stained less densely and the protein bodies prominent in other areas of the endosperm were less obvious. Martinucci et al. (1985) have associated protein bodies in the endosperm of Judas tree seed with a germination inhibitor, ferulic acid. They concluded that this polyphenol was responsible for reducing oxygen availability to the embryo and explained the inhibitory role of the endosperm in embryo dormancy. However, no attempt was made to show that a change in polyphenols in the endosperm was associated with chilling stratification and the release from dormancy.

The evidence presented for eastern redbud and judas tree suggest that the seedcoat and endosperm play a role in maintaining seed dormancy in imbibed seeds that have not been subjected to chilling stratification. However, there is little evidence to suggest that chilling significantly changes the gross anatomical features of the seedcoat. Rather, the evidence in eastern redbud indicates that there are changes in the embryo during chilling stratification that increases its growth potential, allowing the radicle to generate adequate force to penetrate the resistance presented by the seedcoat

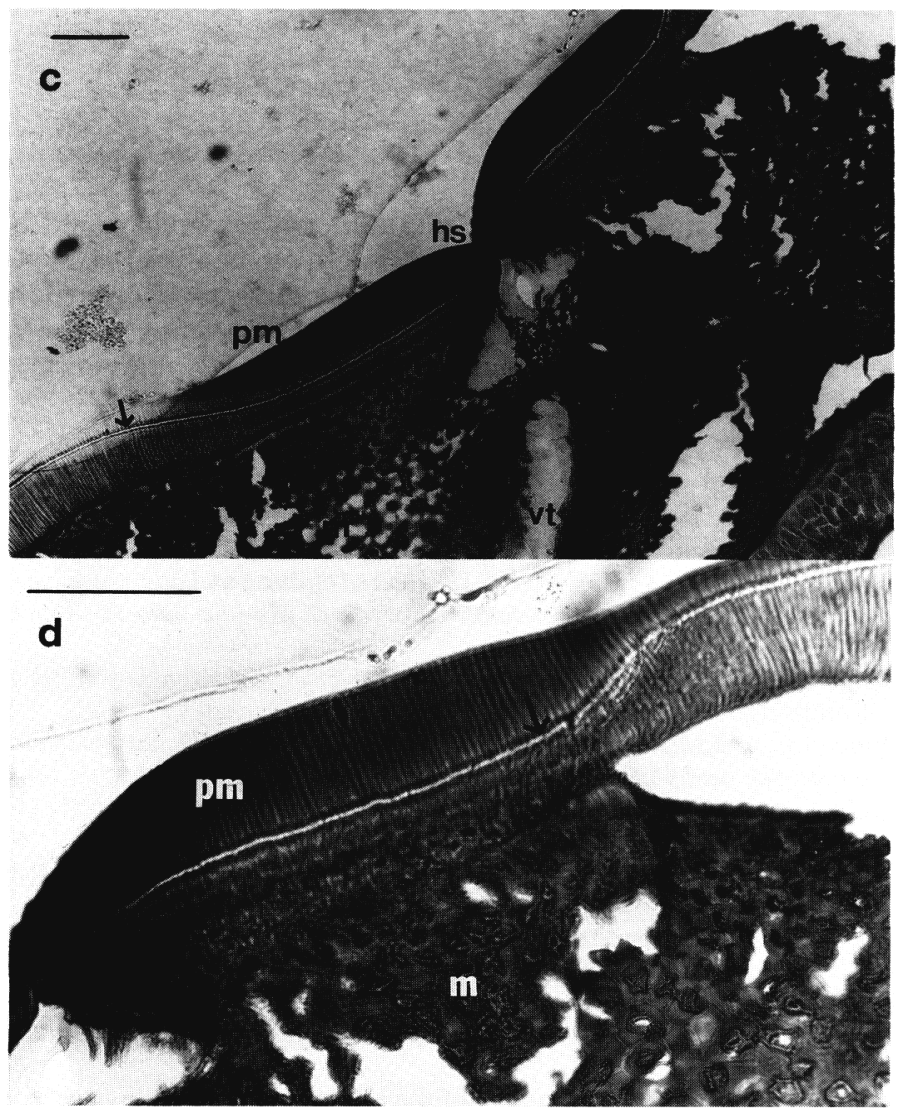

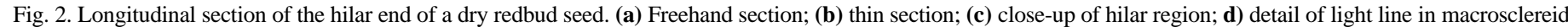

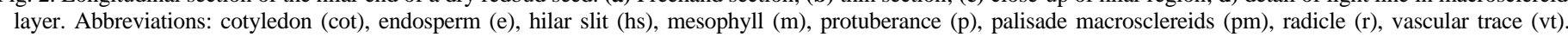
Arrows indicate light line. Reference bars represent $250 \mu \mathrm{m}$ in a and b, $100 \mu \mathrm{m}$ in c and d. 

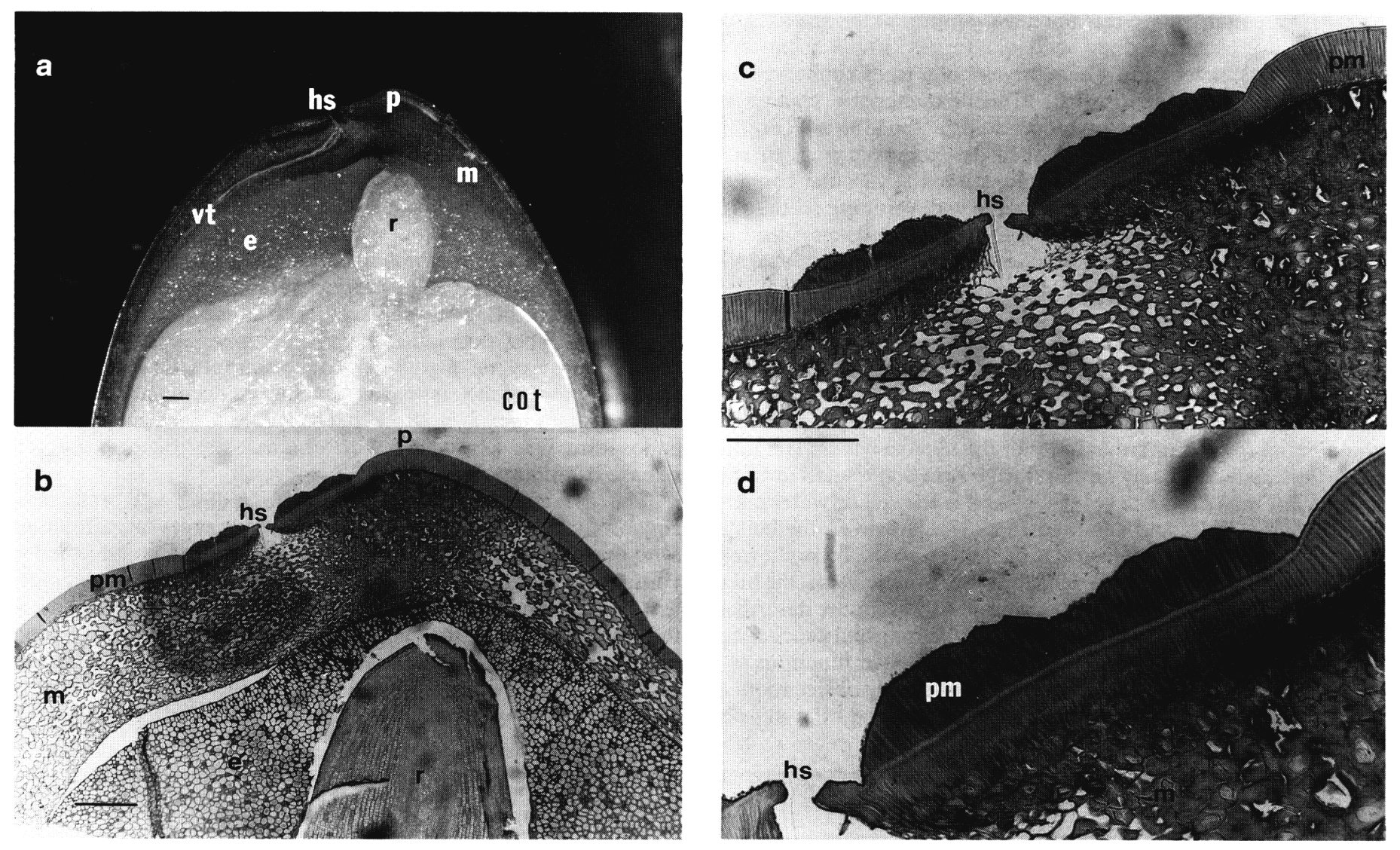

Fig. 3. Longitudinal section of the hilar end of a seed imbibed for $48 \mathrm{~h}$. Panels a-d, abbreviations, arrows, and reference bar are the same as Fig. 2.

and endosperm (Geneve, 1991). Additional research would be needed to determine if this increase in growth potential is due to changes in the water potential and/or wall properties of the cells in the radicle and to what extent cell wall elasticity in the endosperm cells covering the radicle play in the release from dormancy in eastern redbud seeds.

\section{Literature Cited}

Afanasiev, M. 1944. A study of dormancy and germination of seeds of Cercis canadensis. J. Agr. Res. 69:405-420.

Baskin, J.M. and C.C. Baskin. 1971. Effect of chilling and gibberellic acid on growth potential of excised embryos of Ruellia himilis. Planta 100:365-369.

Comer, E.J.H. 1976. The seeds of dicotyledons. Cambridge Univ. Press, Cambridge.

Frett, J.L. and M.A. Dirr. 1979. Scarification and stratification requirements for seeds of Cercis canadensis L. (Redbud), Cladrastis lutea (Mich x. F.) C. Koch (Yellowwood), and Gymnocladus dioicus (L.) C. Koch (Kentucky coffeetree). Plant Prop. 25:4-6.

Gastaldo, P. and P. Profumo. 1975. Tegumento seminale e germinazione in Cercis siliquastrum L. Giorn. Bot. Ital. 109:39-52.

Geneve, R.L. 1991. Seed dormancy in Eastern redbud (Cercis canadensis). J. Amer. Soc. Hort. Sci. 116:85-8.

Gunn, C.R. 1981. Seeds of leguminosae, p. 913-925. In: R.M. Polhill and P.H. Raven (eds.). Advances in legume systematics. Royal Botanic Gardens, Kew, England.

Hyde, E.O.C. 1954. The function of the hilum in some Papilionaceae in relation to the ripening of the seed and permeability of the testa. Ann. Bot. 18:241-256.

Kelly, K.M. and J. van Staden. 1987. The lens as the site of permeability in the papilionoid seed, Aspalathus linearis. J. Plant Physiol. 128:395-404.

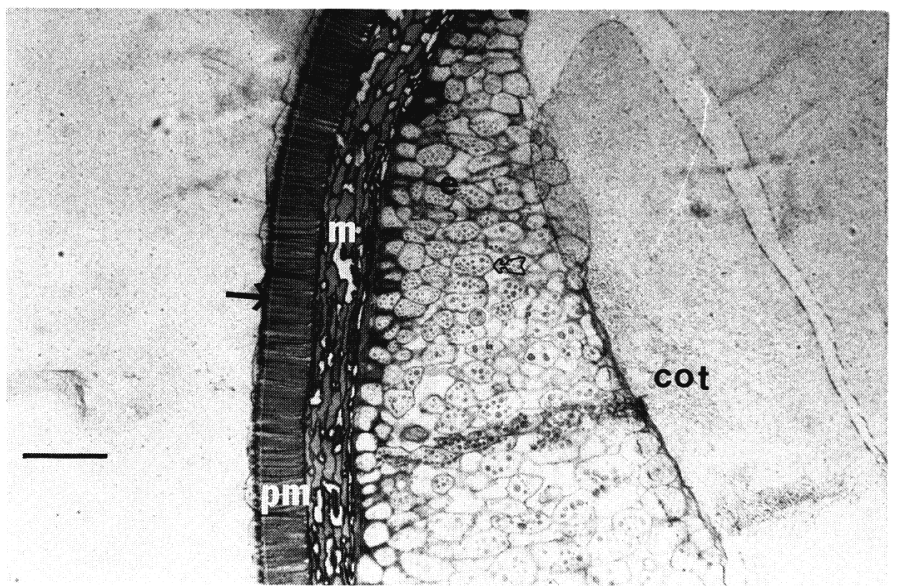

Fig. 4. Cross section of a redbud seed imbibed for $48 \mathrm{~h}$. Closed arrow indicates location of the light line in macrosclereids. Open arrow indicates stained protein bodies. Abbreviations same as Fig. 2. Reference bar represents $100 \mu \mathrm{m}$.

Lang, G.A., J.D. Early, G.C. Martin, and R.L. Darnell. 1987. Endo-, para, and ecodormancy: Physiological terminology and classification for dormancy research. HortScience 22:371-377.

Manning, J.C. and J. van Staden. 1987. The functional differentiation of the testa in seed of Indigofera parviflora (Leguminosae: Papilionoideae). Bot. Gaz. 148:23-24.

Martin, J.N. and J.R. Watt. 1944. The strophiole and other seed structures associated with hardness in Melilotus alba L. and M. officinalis Willd. Iowa State College J. Sci. 18:457-469. 

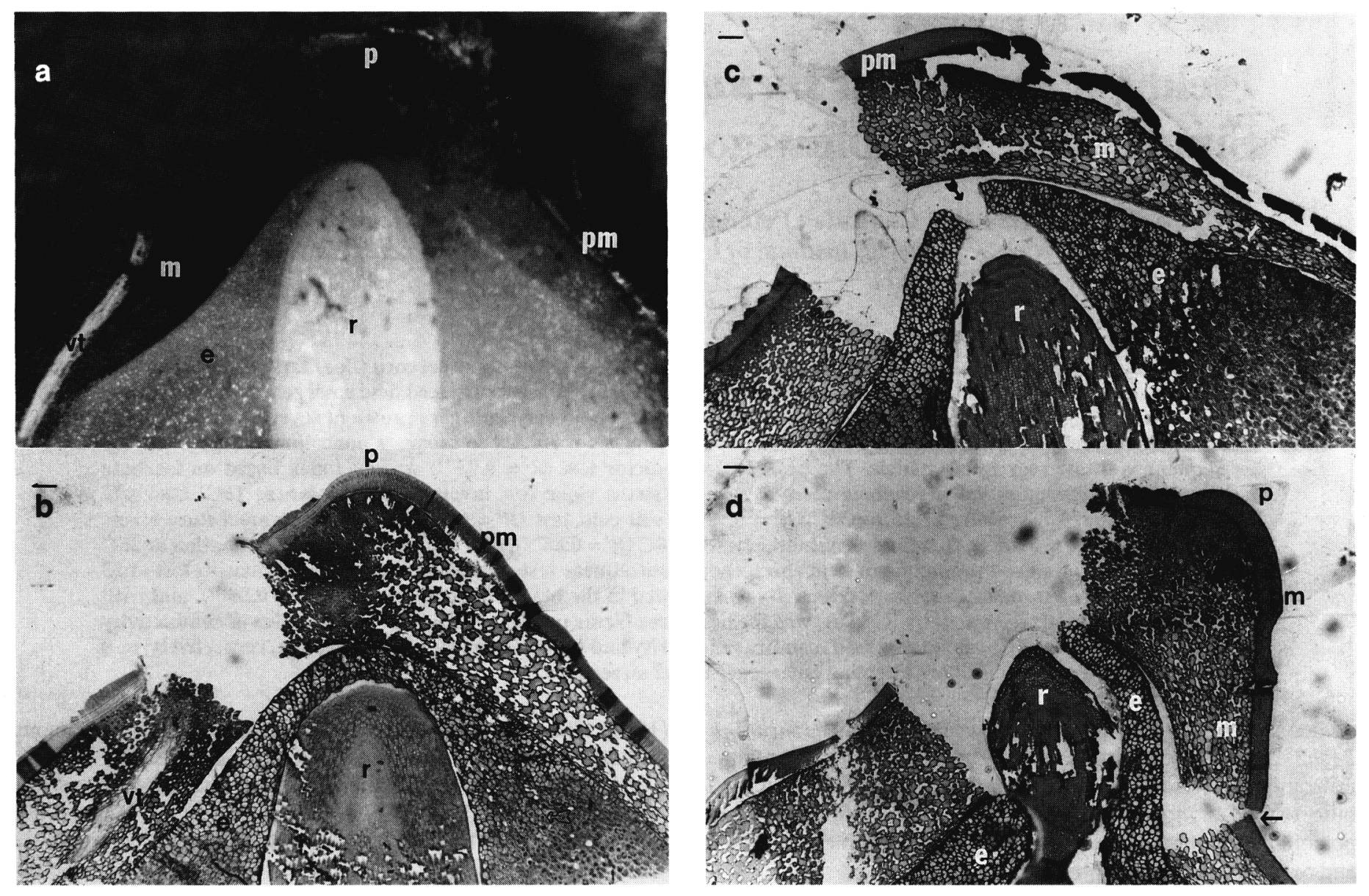

Fig. 5. Longitudinal section of the hilar end of a germinating redbud seed. (a) Freehand section; (b) thin section with seedcoat separating to form the cap with the endosperm intact; open arrows indicate staining of protein bodies; (c) endosperm ruptured above root apex (solid arrow); (d) radicle pushing endosperm and seedcoat cap aside. Solid arrow indicates macrosclereid forming a hinge for the seedcoat cap. Abbreviations and reference bar are the same as Fig. 2.
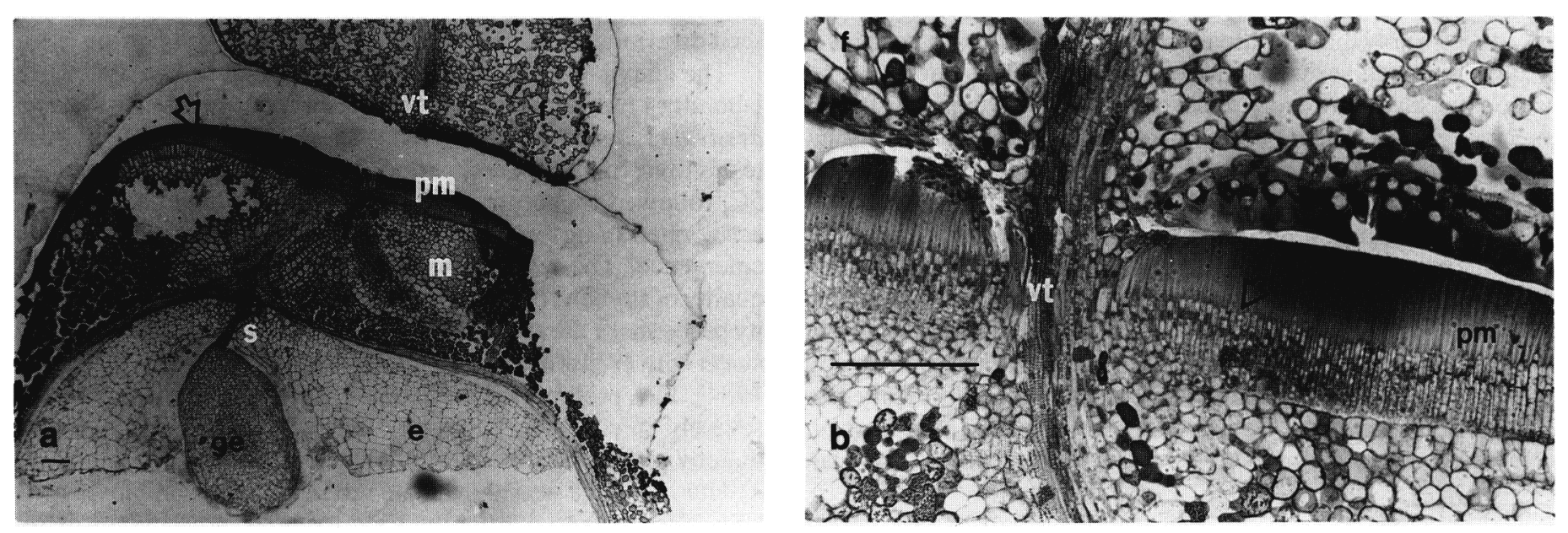

Fig. 6. (a) Longitudinal section of a developing ovule $\approx 57$ days postanthesis. (b) Close-up detail of vascular trace traversing from the funiculus into the ovule. Abbreviations: endosperm (e), funiculus (f), globular embryo (ge), mesophyll (m), palisade macrosclereids (pm), suspensor (s), vascular trace (vt). Arrow indicates lightline in macrosclereids. Reference bar represents $100 \mu \mathrm{m}$

Martinucci, R., P. Gastaldo, P. Profumo and L.R. Bevilacqua. 1985. Bound ferulic acid in the endosperm of Cercis siliquastrum L. Plant Sci. 38:41-46.

Profumo, P. and P. Gastaldo. 1977. Ulteriori ricerche sulla germinazione di Cercis siliquastrum L. Asione dell'acido gibberellico ruolo dell'endosperma nel fernomeno della dormienza. Giorn. Bot. Ital.
111:211-218.

Serrato-Valenti, G., L. Cornara, S. Lotito and L. Quagliotti. 1992. Seed coat structure and histochemistry of Abelmoschus esculentus. Chalazal region and water entry. Ann. Bot. 69:313-321.

Winter, D.M. 1960. The development of the seed of Abutilon theophrasti. II. Seed Coat. Amer. J. Bot. 47:157-162. 